\title{
Design and Simulation of RF MEMS Capacitive type Shunt Switch \& its Major Applications
}

\author{
Poonam Verma ${ }^{1}$, Surjeet Singh ${ }^{2}$ \\ ${ }^{\prime}$ (M. Tech Scholar, I.E.T, Bhaddal, Ropar, Punjab, India) \\ ${ }_{2}^{2}$ (Assistant Professor, Dept. of Electronics and Communication, I.E.T, Bhaddal, Ropar, Punjab, India)
}

\begin{abstract}
This article details about the design of a K-band RF-MEMS capacitive type shunt switch and some of its major applications. The electrostatic and electromagnetic analyses of the designed structure have been performed using MATLAB and commercially available EM solvers. FEM and MOM both tools have been used extensively for full-wave analysis. Two major applications (SPDT switch and reconfigurable Antenna) have been studied here. The design is based upon $675 \mu \mathrm{m}$ thick high resistive Silicon $(\rho>8 \mathrm{~K} \Omega$-cm).
\end{abstract}

Keywords - Coplanar waveguide, MEMS Shunt switch, Reconfigurable Antenna, RF MEMS, Single Pole double throw (SPDT)

\section{INTRODUCTION}

A micro-electromechanical system (MEMS) is a process technology used to produce minute integrated devices or systems that merge mechanical and electrical components. RF-MEMS switches are playing a crucial role in the growth of the modern communications systems. The MEMS switches have the capability to combine advantages of electro-mechanical and semiconductor technologies based switches. In particular, MEMS switches offer the high RF performance and low DC power consumption of electro-mechanical switches but with the size and cost features of semiconductor switches [1]. RF MEMS switch found extensive applications in switching networks, T/R modules, phase shifters, reconfigurable antennas, tunable and switched filter banks etc. A MEMS switch can be made in several different configurations depending on the signal path (series or shunt), the actuation mechanism (electrostatic, magneto static, thermal etc), the type of contact (Ohmic or capacitive) and the type of structure (cantilever or bridge). Various kinds of MEMS switches have been extensively studied in series and shunt structures [2]-[3]. In 1996, the first practical capacitive shunt switch was presented by Raytheon based on a fixed-fixed metal beam design [2]. Since then, several studies have been conducted on capacitive shunt switches to achieve better performance and lower actuation voltage [4]-[9]. In this paper, design of RF MEMS switches based on simple fixed-fixed beam has been carried out. A shunt-capacitive MEMS switch consists of a thin metal membrane "bridge" suspended over the center conductor of a coplanar waveguide (CPW) [10]-[11] or microstrip line and fixed at both ends to the ground conductors of the CPW line as shown in fig. 1(a). In this paper, electrostatic and electromagnetic simulation results of RF MEMS capacitive shunt switches for K-band (18-26.5 GHz) applications have been carried out. MATLAB has been used for Electrostatic simulation and ADS \& HFSS have been used extensively for EM simulations. RF MEMS switches have been extensively used for reconfigurable integrated circuits [12]. Furthermore a SPDT MEMS switch and a Ka-band Reconfigurable patch antenna with the use of integrated MEMS switches are also presented. The experimental results show the insertion loss of SPDT switch is below $0.3 \mathrm{~dB}$ and the isolation obtained is better than $18 \mathrm{~dB}$ entirely up to $\mathrm{K}-$ band. The organization of the paper is as follows. RF MEMS switch with its selection criteria, parameters are discussed in Section 2. Electrostatic and Electromagnetic analysis of Capacitive Shunt switches are discussed in Section 3 and Section 4 respectively. Section 5 presents applications of MEMS switch.

\subsection{RF MEMS Capacitive Shunt switch for $K$ band}

\section{RF MEMS SWITCH}

Switches are the fundamental and imperative parts of RF systems. RF MEMS switch are highly attractive for low loss, high isolation, high linearity, wide band, low power consumption and ease of integration. These switches can be mainly categorized as Capacitive and Ohmic contact and the signal can flow in series and shunt configuration as shown in table I. There are two main forces for the actuation purpose of RF MEMS switch: Electromagnetic and Electrostatic and the properties of these two actuation methods are given in table II. 
Table I

Classification of Switch

\begin{tabular}{|l|l|}
\hline \multicolumn{1}{|c|}{ Parameters } & \multicolumn{1}{c|}{ Type } \\
\hline Contact type & Series Configuration \\
\cline { 2 - 2 } & Shunt Configuration \\
\hline Mechanical structure & Cantilever \\
\cline { 2 - 2 } & Fixed-fixed beam \\
\hline Form of Contact & Capacitive \\
\cline { 2 - 2 } & Ohmic \\
\hline
\end{tabular}

Table II

Actuation properties Vs Actuation Method

\begin{tabular}{|l|l|l|l|}
\hline $\begin{array}{c}\text { Actuation } \\
\text { method }\end{array}$ & \multicolumn{1}{|c|}{$\begin{array}{c}\text { Power } \\
\text { usage }\end{array}$} & $\begin{array}{c}\text { Force } \\
\text { Generated }\end{array}$ & Speed \\
\hline Thermal & High & Moderate & $\mathrm{m} \mathrm{sec}$ \\
\hline $\begin{array}{l}\text { Electromagne } \\
\text { tic }\end{array}$ & $\begin{array}{l}\text { Medium/Hi } \\
\text { gh }\end{array}$ & High & $\begin{array}{l}\mu \mathrm{sec} / \\
\mathrm{m} \mathrm{sec}\end{array}$ \\
\hline Electrostatic & low & Moderate & $\mu \mathrm{sec}$ \\
\hline
\end{tabular}

As it can be seen from the table II, in case of the electromagnetic actuation, the usage of power and the force generated are high as compared to electrostatic actuation method. So for the microwave and mm-wave regions, electrostatic switches are the most common switches that are used [13].

\subsection{Switch Selection}

Different parameters are considered for switch selection as shown in Table I. The main criteria for the selection of the switch are frequency of operation and application. Out of the two configuration, shunt is preferred over series due to minimal parasitic involved and can handle four times more RF power compared to series switch. The series configuration mostly applied at the lower frequencies. In series configuration, the $t$-line is open when no bias voltage is applied (up-state position). The open contact of the transmission lines at K-band frequencies propagates the surface modes which hinders the operation of series switches at higher frequencies. The advantage of implementing shunt switch are ease of fabrication, for the same specifications the value of down-state capacitance is low for series configuration as compared to shunt type, resulting in poor isolation of series switches at high frequencies, Shunt configuration in comparison to series have fewer parasitic due to continuous t-line and mainly in the down-state, the isolation of the series switch design is limited by the coupling between the two open conductors. Fig. 1(a) and fig. 1(b) shows the cross sectional view and isometric view of RF MEMS capacitive shunt switch respectively for the high frequency applications which is designed and simulated electro-statically and electromagnetically using 2.5D and 3D full wave EM simulators [14].

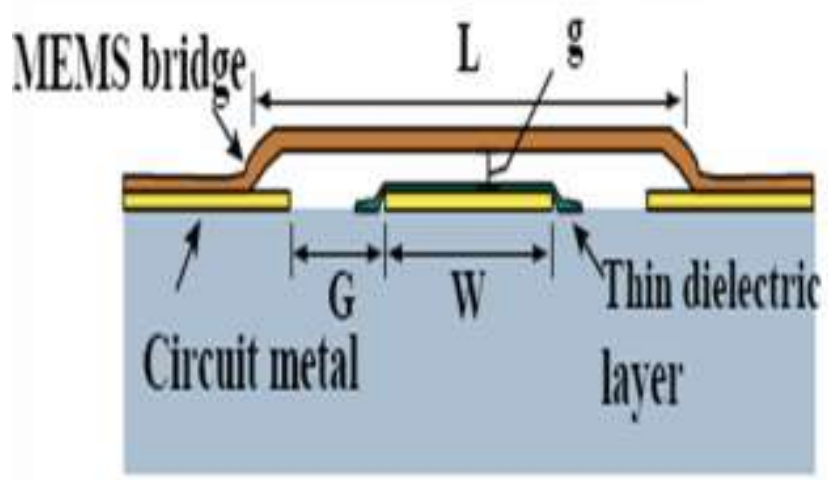

(a)

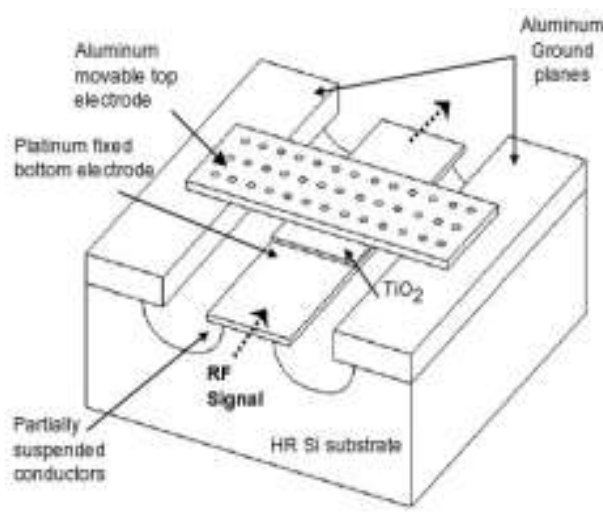

(b)

Fig. 1 Shunt Capacitive Switch (a) Cross sectional view (b) Isometric view

\section{ELECTROSTATIC ANALYSIS OF SWITCH}

Capacitive switches are two-state capacitors. The typical switch is a metal bridge suspended above a CPW signal line with both ends of the bridge anchored to ground. The switch has the minimal loading effect on the signal line in this state (the passing state) and signals propagate with minimal reflection. The switch is snapped down when a voltage exceeding the electrostatic pull-in voltage is applied between the bridge and the signal line. In this state (the down-state) incident signals are reflected due to the formation of a low impedance path through the dielectric and the switch bridge to ground. The level of isolation depends on the relative value of the shunt impedance to the characteristic impedance of the transmission line, Zo. The ratio of the blocking state (down-state) capacitance to the passing state (up-state) capacitance, $C_{o n} / C_{o f f}$, is often used as a performance metric known as figure of merit, which should be more than 50. Generally, capacitive switches are used in the shunt configuration. 


\subsection{Coplanar Waveguide}

Coplanar waveguide (CPW) is a Planar transmission line. In this Signal line and two ground lines are on the same plane. It is a substrate height independent transmission line. The $\mathrm{Z}_{0}$ of the line is determined by G/W/G dimension. It is easy for Calibration. The thickness of dielectric in ideal CPW is infinite. There are various configurations of CPW and these can be classified as Simple CPW, CB-CPW (Conductor backedCoplanar waveguide), FG-CPW (Finite ground-Coplanar waveguide),FG-CB-CPW(Finite ground-Conductor backed-Coplanar waveguide) where $\mathrm{w}$ is center strip width and $\mathrm{S}$ is slot width and $\mathrm{C}_{\mathrm{r}}$ is relative dielectric constant of the substrate dielectric. This design uses the silicon substrate of $\epsilon_{\mathrm{r}}=11.8$, and CPW center conductor width of $\mathrm{w}=120 \mu \mathrm{m}$, space line is $90 \mu \mathrm{m}$, the thickness is $1 \mu \mathrm{m}$ and the height of the substrate is $675 \mu \mathrm{m}$.

\subsection{Switch Parameters}

Increasing the substrate permittivity and thinning the substrate reduces loss, however thinning these substrates are difficult to handle and can result in high yield loss. So in the given scenario High Resistive Silicon $(\rho>8 K \Omega-\mathrm{cm})$ has been opted. The modeled parameters of the shunt switch using the above CPW line are shown in table III. As per the values chosen for length (l), width of membrane(w), Central electrode width of the CPW line (W), thickness $(\mathrm{t})$,gap-height $\left(g_{0}\right)$, some another parameters had been calculated and given in table IV.

Table III

Modeled values of switch

\begin{tabular}{|c|c|}
\hline Parameters & Values \\
\hline $\begin{array}{l}\text { Up-state Capacitance } \\
\left(\mathrm{C}_{\mathrm{u}}\right)\end{array}$ & 82 \\
\hline $\begin{array}{l}\text { Down-state capacitance } \\
\left(\mathrm{C}_{\mathrm{d}}\right)\end{array}$ & $6.36 \mathrm{pF}$ \\
\hline Inductance $\quad(\mathrm{L})$ & $14.18 \mathrm{pH}$ \\
\hline Resistance $\quad(\mathrm{R})$ & $0.158 \Omega$ \\
\hline Length & $300 \quad \mu \mathrm{m}$ \\
\hline Width & $100 \mu \mathrm{m}$ \\
\hline Initial air-gap $\left(\mathrm{g}_{\mathrm{o}}\right)$ & $\mu \mathrm{m}$ \\
\hline Thickness & 0.5 \\
\hline Membrane & $\begin{array}{l}\text { Gold }(\mathrm{Au}) \\
\text { Aluminium(Al) }\end{array}$ \\
\hline$(\mathrm{G} / \mathrm{W} / \mathrm{G})$ & $90 / 120 / 90 \mu \mathrm{m}$ \\
\hline Substrate & $\begin{array}{l}\text { High Resistive Silicon } \\
(\rho>8 K \Omega-c m)\end{array}$ \\
\hline Actuation area & $120 \times 100 \mu \mathrm{m}^{2}$ \\
\hline
\end{tabular}

Table IV

Calculated Parameters

\begin{tabular}{|l|c|c|}
\hline \multirow{2}{*}{ Parameters } & \multicolumn{2}{|c|}{ Values } \\
\cline { 2 - 3 } & $\begin{array}{c}\text { Gold } \\
\text { Membrane }\end{array}$ & $\begin{array}{c}\text { Aluminium } \\
\text { Membrane }\end{array}$ \\
\hline $\begin{array}{l}\text { Spring constant } \\
(\mathrm{N} / \mathrm{m})\end{array}$ & 14.93 & 17.33 \\
\hline $\begin{array}{l}\text { Pull-down } \\
\text { Voltage (Volt) }\end{array}$ & 35 & 37.5 \\
\hline $\begin{array}{l}\text { Charge storage } \\
(\text { fC) }\end{array}$ & 3.1 & 3.3 \\
\hline $\begin{array}{l}\text { Actuating } \\
\text { Voltage (Volt) }\end{array}$ & 38 & 41 \\
\hline $\begin{array}{l}\text { Electrostatic } \\
\text { Force ( } \mu \mathrm{N})\end{array}$ & 8.49 \\
\hline $\begin{array}{l}\text { Hold-on Voltage } \\
\text { (Volt) }\end{array}$ & \multicolumn{2}{|c|}{11} \\
\hline
\end{tabular}

\section{V. Electromagnetic ANALYSis Of SWITCH}

The key characteristics of the RF MEMS switch are insertion loss, isolation, and actuation voltage. The aim is to increase the RF parameters while reducing the actuation voltage. A MEMS shunt capacitive switch in upstate and downstate position is shown in fig. 2(a) and fig. 2(b) respectively. The layout designs of switch are shown in fig. 3(a) and fig. 3(b). The switch is suspended at a height ' $g$ ' above the dielectric layer on a t-line and the dielectric thickness is $t_{d}$ with the dielectric constant $\epsilon_{r}$. The switch is $\mathrm{L} \mu \mathrm{m}$ long, w $\mu \mathrm{m}$ wide and $\mathrm{t} \mu \mathrm{m}$ thick. The width of t-line is $\mathrm{W} \mu \mathrm{m}$. The switch is modeled by two short sections of $\mathrm{t}$-line and a lumped CLR model of the bridge with a variable capacitor (up-state, down-state). 


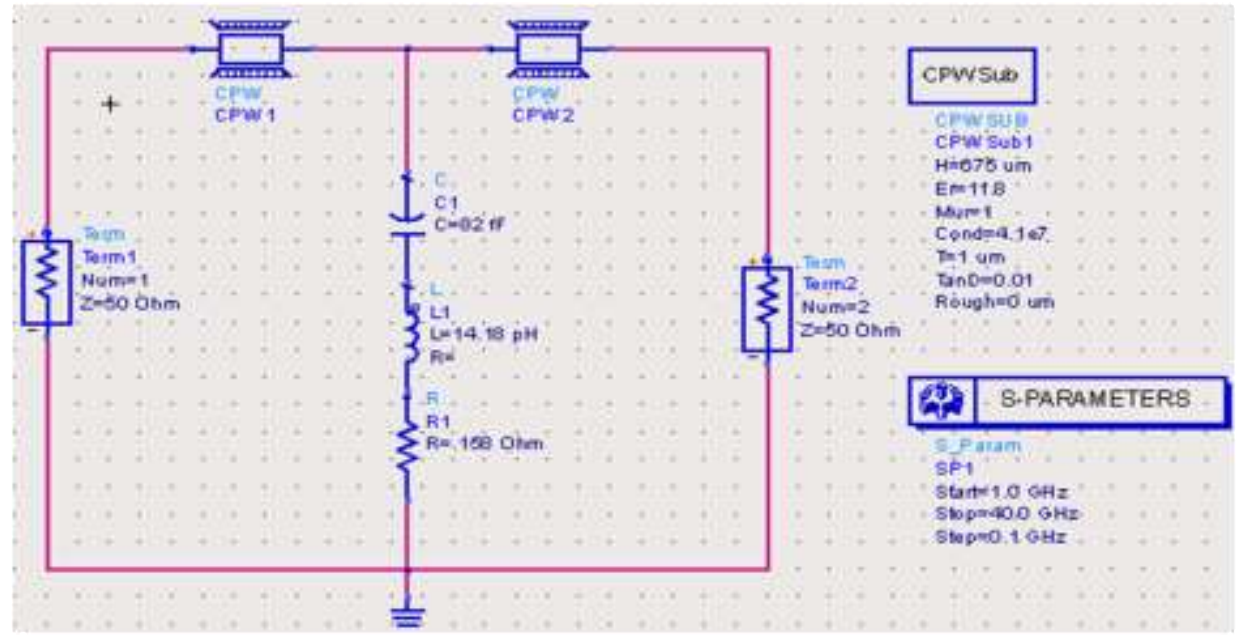

(a)

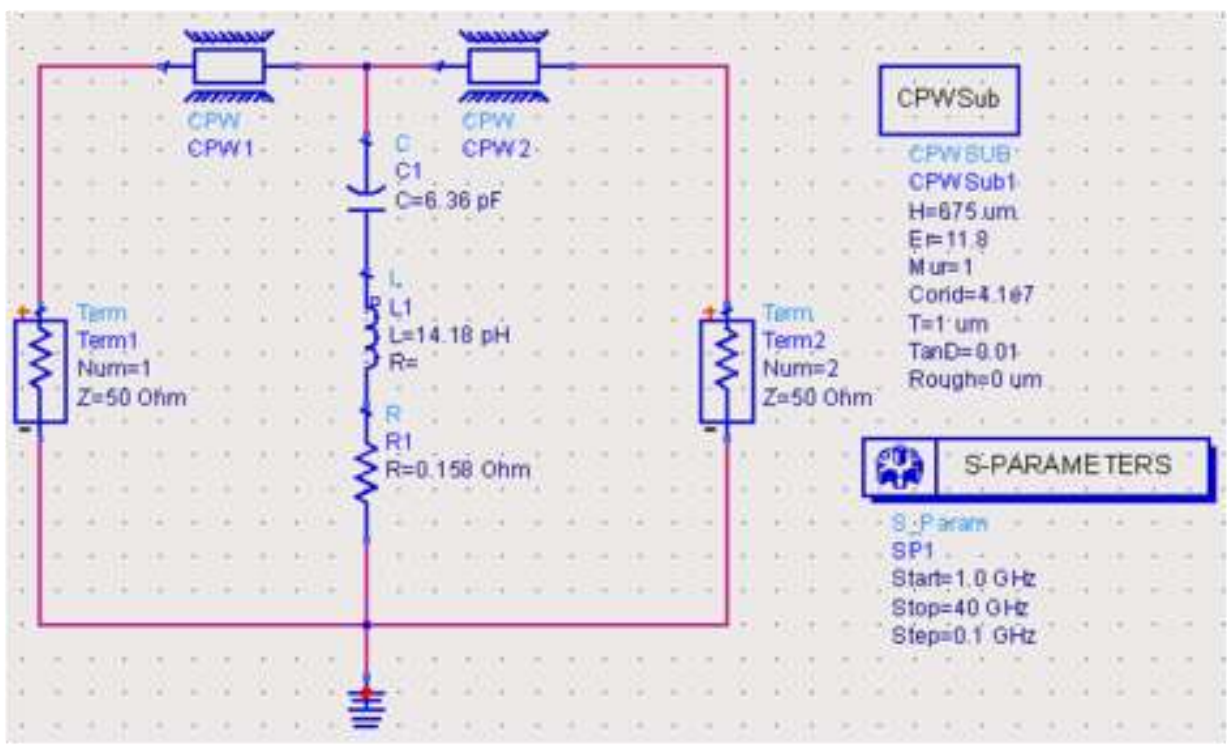

(b)

Fig. 2 Schematic model of Shunt capacitive switch in (a) Upstate position (b) Downstate position

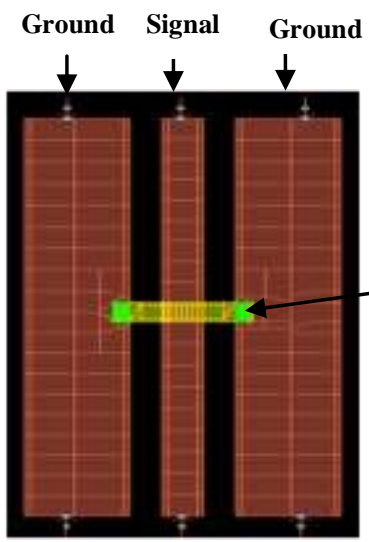

(a)

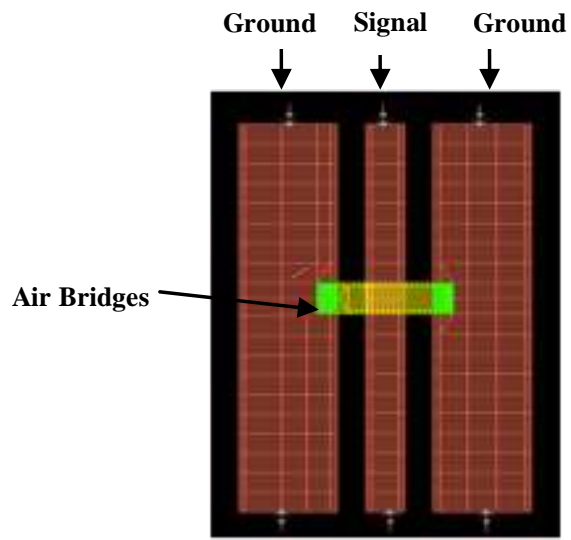

(b)

Fig. 3 Layout structure of Shunt capacitive switch in (a) Upstate position (b) Downstate position 


\subsection{5- D and 3-D Simulation of RF Switch}

Upstate Simulation: The switch structure is simulated in the upstate position by the ADS and HFSS simulators. There is CPW which contains transmission line, a substrate, and grounds. There are two anchors situated on top of the CPW and connects the membrane to the Ground [9]. The area of the membrane is $120 \times 100 \mu^{2}$. The S parameters are taken from the range of $0-40 \mathrm{GHz}$ using the ADS. As can be seen from fig. 4(a), the Return loss $\left(S_{11}\right.$ is better than $10 \mathrm{~dB}$ in the frequency range of DC $-35 \mathrm{GHz}$, Insertion loss $\left(S_{12}\right)$ is less than $0.3 \mathrm{~dB}$. In HFSS simulator, the Return loss $\left(\mathrm{S}_{11}\right.$ is better than $10 \mathrm{~dB}$ in the frequency range of DC - 30 $\mathrm{GHz}$, Insertion loss $\left(S_{12}\right)$ is less than $0.3 \mathrm{~dB}$ as shown in fig. 6 .

Downstate simulation: The switch in its downstate position does not have anchors because the membrane should be situated on top of the dielectric layer [9]. The S-parameters are taken from the range of $0-16 \mathrm{GHz}$ using the ADS. As can be seen from fig. 4(b), Isolation $\left(S_{21}\right)$ is better than $20 \mathrm{~dB}$ in frequency band of 5-40 $\mathrm{GHz}$

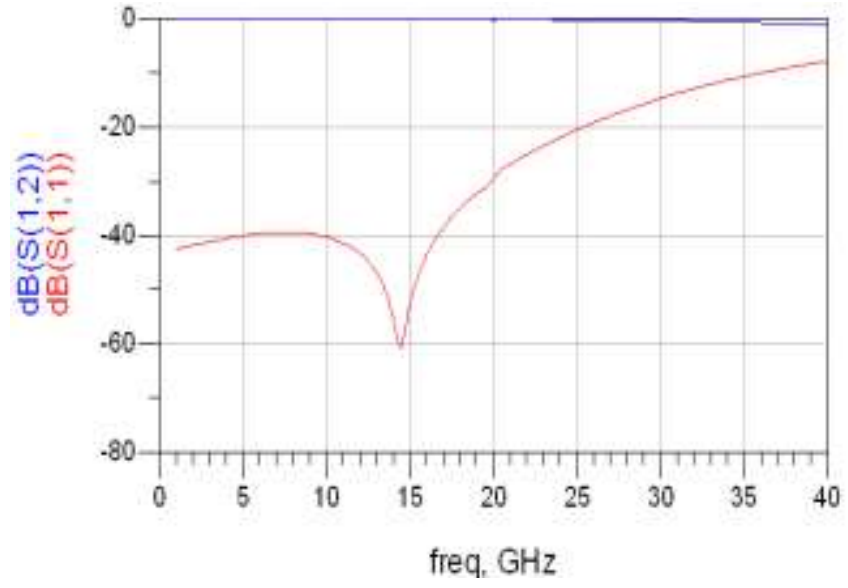

(a)

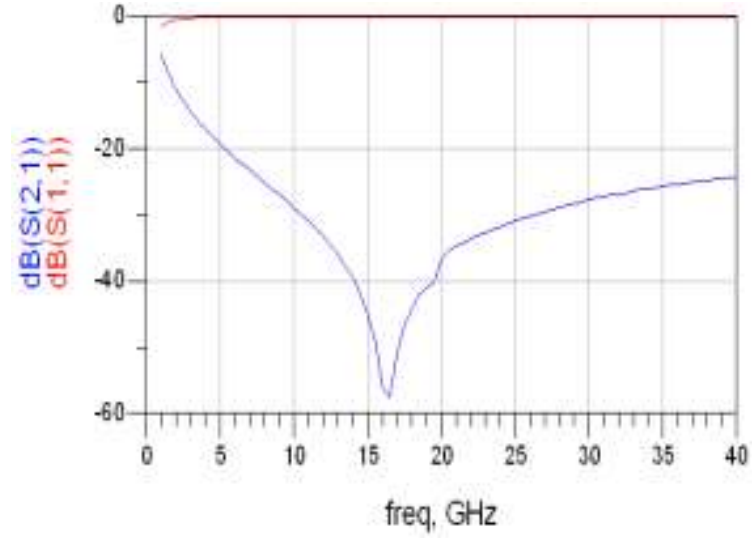

(b)

Fig. 4 (a) Return loss $S(1,1)$, Insertion loss $S(1,2)$ (b) Isolation $S(2,1)$

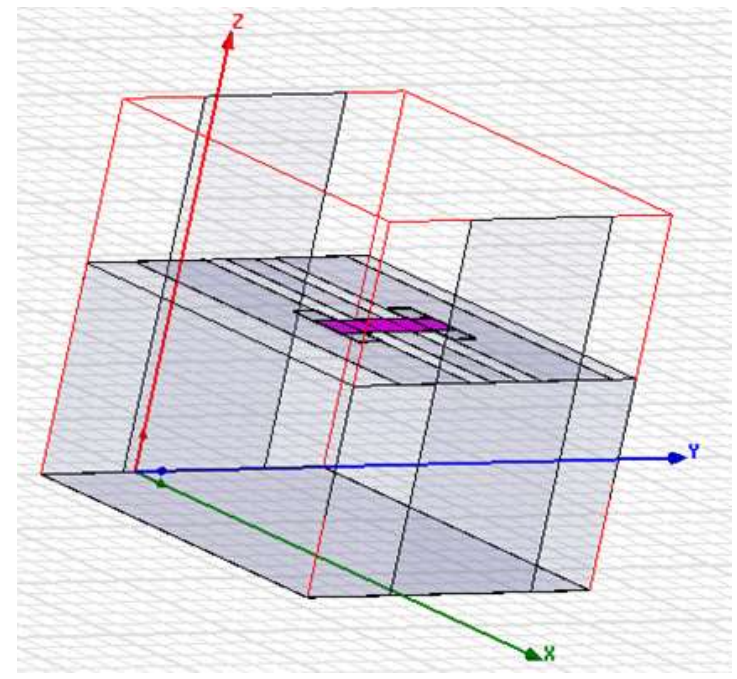

Fig. 5 RF switch structure in HFSS Simulator 


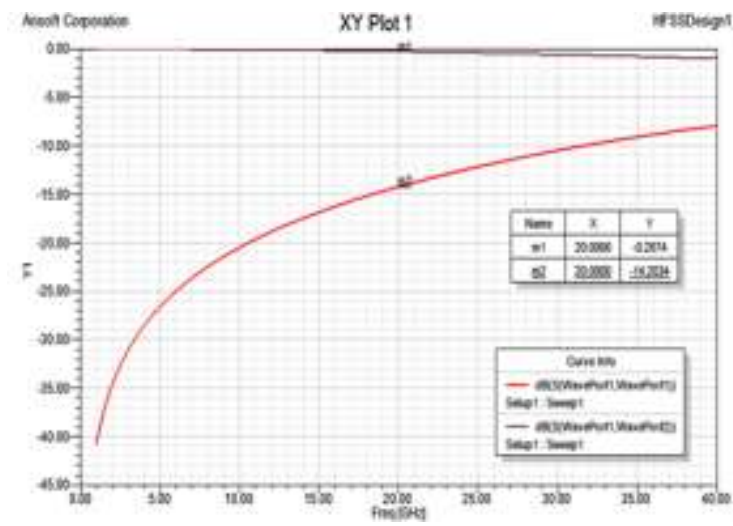

Fig. 6 Measured Return loss $\mathrm{S}(1,1)$ and Insertion loss $\mathrm{S}(1,2)$ of Shunt capacitive switch

\section{APPlications Of Rf Mems Switch}

To have faster, cheaper, highly tunable Communication system which is having wider bandwidth for increased data rates as per the requirement for which MEMS devices have originated new field of applications. Reconfigurable antennas, filters and tuners, high-Q passives and resonators, low loss planar $\mathrm{THz}$ waveguide components and low loss phase shifters having low loss and high isolation are a few applications of RF MEMS switches. Out of many applications major applications are designed and simulated.

\subsection{SPDT MEMS Switch}

The single-pole double-throw (SPDT) switches have been broadly employed in the microwave and millimeter wave communication systems [15], such as the signal routing in transmit and receive applications, the switched-line phase shifters, phased array antennas and the wide-band tuning networks. Many SPDT switches were implemented using MEMS technology for replacing the conventional solid state semiconductor switches. In this paper, a MEMS SPDT switch has been employed to work in K-band applications (10-30 G Hz).

\subsection{Design and EM Simulation of MEMS SPDT Switch}

The layout structure of capacitive SPDT switch in state 1 and state 2 shown in fig. 7(a) and fig. 7(b) respectively. When the switch pair $S_{1}$ is open and the $S_{2}$ is closed, the RF power flows from the input to the RF out 1 and vice versa. When the SPDT switch is in state 1 then insertion loss is at $S_{21}$ terminal and Isolation is at $S_{31}$ terminal and the same way when this SPDT switch is in state 2 Insertion loss is at $S_{31}$ terminal and Isolation is at $S_{21}$ terminal. The SPDT switch consists of two pairs of capacitive MEMS shunt switches and a power splitter. The pairs of MEMS switches are used to enhance the isolation between the two output ports, and they are at a quarter-wavelength distance from the T-junction. The quarter-wavelength transmission lines between the T-junction and the switch pairs are capacitively loaded with two air bridges in order to make the SPDT switch more compact in size. RF performance of the SPDT switch has been analyzed using 2.5D planar electromagnetic software, ADS.

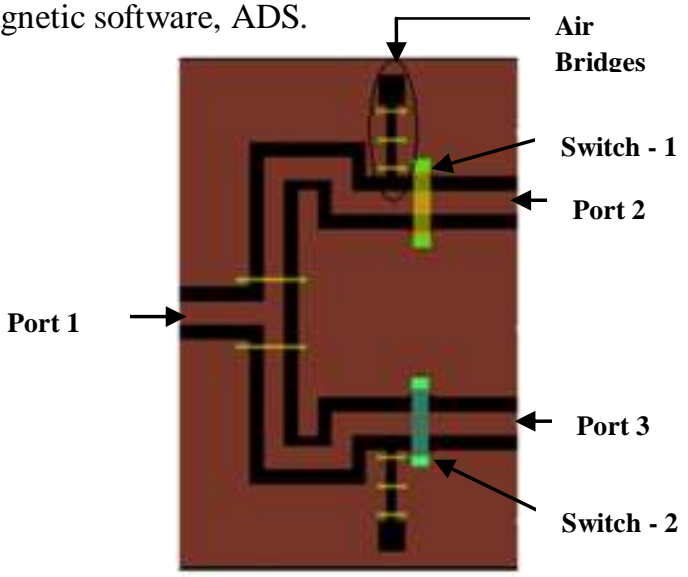

(a)

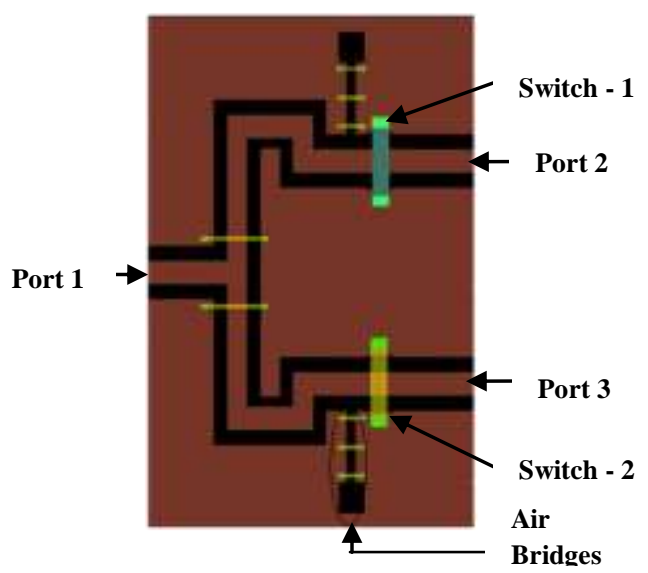

(b)

Fig. 7 Layout structure of the capacitive MEMS SPDT switch (a) State-1 (b) State-2 
As shown in Fig. 8(a)-8(c), in state 1, the simulated return loss is better than $10 \mathrm{~dB}$ in the frequency range of $10-25 \mathrm{GHz}$, Insertion loss is less than $0.3 \mathrm{~dB}$, Isolation is between two ports i.e. $\left(\mathrm{S}_{32}\right)$ is better than 18 $\mathrm{dB}$ entirely upto $\mathrm{K}$ - band and the simulated Insertion loss is also less than $0.3 \mathrm{~dB}$ in state 2 as shown in fig. 8 (d)

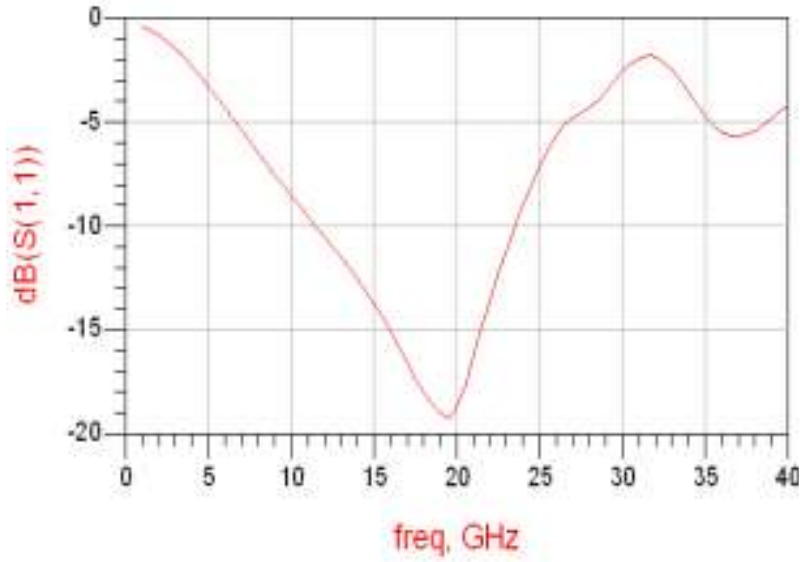

(a)

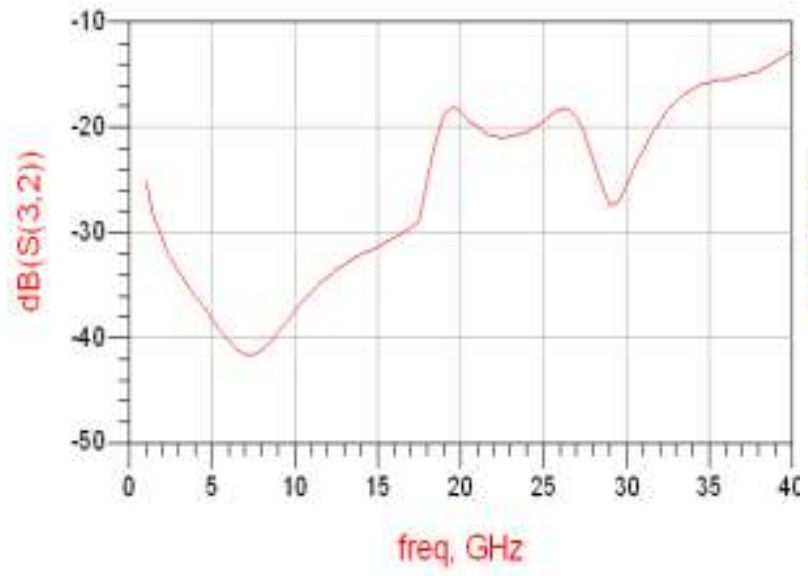

(c)

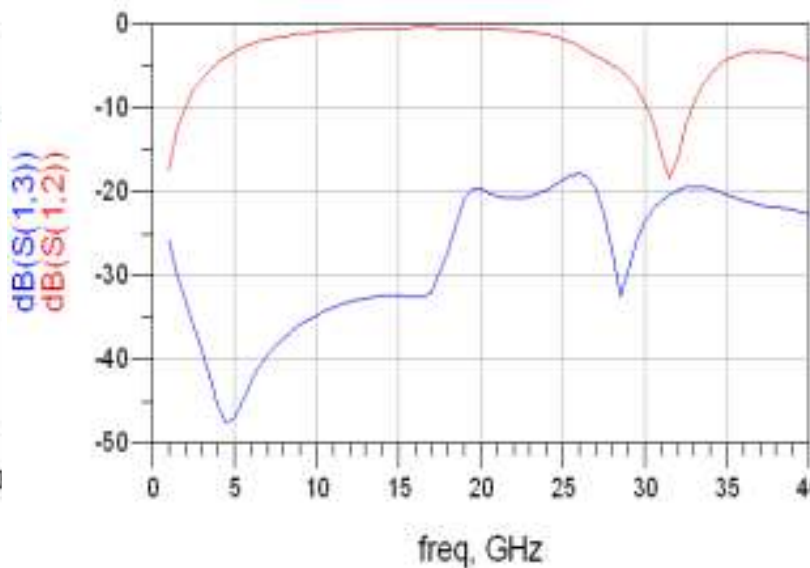

(b)

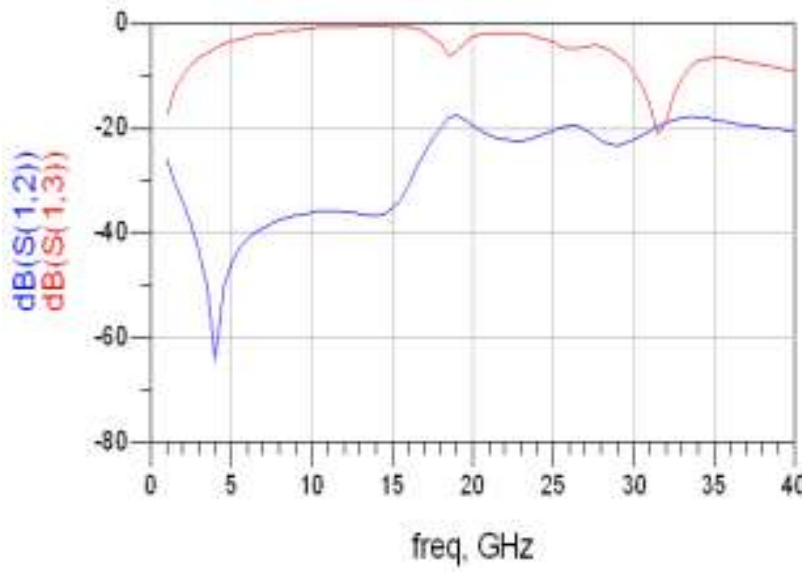

(d)

Fig. 8 Result of SPDT switch in State -1 (a)Return loss $\mathrm{S}(1,1)$ (b) Insertion loss $\mathrm{S}(1,2)$ (c) Isolation $\mathrm{S}(3,2)(\mathrm{d})$ SPDT switch in State -2

\subsection{Reconfigurable Patch Antenna}

The new generation of antennas is Reconfigurable antenna that will not be limited to a certain function or resonance but will change their functionality depending on the requirements of implementation. As compared to broadband antennas, reconfigurable antennas offer many advantages, such as compact size, radiation patterns for all designed frequency bands are somewhat similar, and frequency selectivity which helps in reducing adverse effects like jamming and co-site interference.

\subsection{Design and EM Simulation of Reconfigurable Patch Antenna}

A new field of modern world microwave is the reconfigurability of the already used devices in the system chain. It is gaining maximum potentiality because of its versatile utility according to desired environments [16].A Ka-band reconfigurable microstrip Patch antenna has been designed and simulated using EM Simulators as shown in fig.9, based on a structure with RF MEMS switches mounted at different slots. The states of the switches change the functionality of the antenna cutting or allowing certain frequencies of operation. The main feature of this approach is (1) for providing polarization diversity, the capability of a square patch to dynamically reconfigure the polarization from circular to linear, thus and (2) the MEMS switches with the dimensions of length $=400 \mu \mathrm{m}$, width $=100 \mu \mathrm{m}$, thickness $=1 \mu \mathrm{m}$ is mounted within the patch and does not require supplementary space. The MEMS switches consists of a moveable metal overpass suspended over a $\mathrm{T}$ shaped Metal stub. The overpass is supported at both ends by metalized vias which are electrically connected to the patch antenna. The metal overpass is actuated by an electrostatic force of attraction set up by a voltage applied between the overpass and the T- shaped metal stub. A dielectric layer having high resistive silicon 
substrate of $0.675 \mathrm{~mm}$ deposited over the metal stub prevents stiction when the surfaces come in contact. The metal strip of length $570 \mu \mathrm{m}$ and width $50 \mu \mathrm{m}$ attached to the metal stub behaves as a parallel plate Capacitor shown in fig. 9 .The switch is in the ON state when the overpass is pulled down by the electrostatic force due to the bias, and the capacitance of the metal strip appears in shunt with the input impedance of the patch antenna. This capacitance tunes the patch to a lower operating frequency. When both the switches are in the OFF state (upstate), the patch resonates at its nominal operating frequency ( $f_{o}$ ) of about $29.0 \mathrm{GHz}$. When both switches are in the ON state (downstate), the $\mathrm{f}_{\mathrm{ON}}$ is $28.5 \mathrm{GHz}$. The reconfigurable patch antenna structure is shown in fig. 10 and measured return loss demonstrating frequency reconfigurability is about $-13.3 \mathrm{~dB}$ in HFSS simulator .

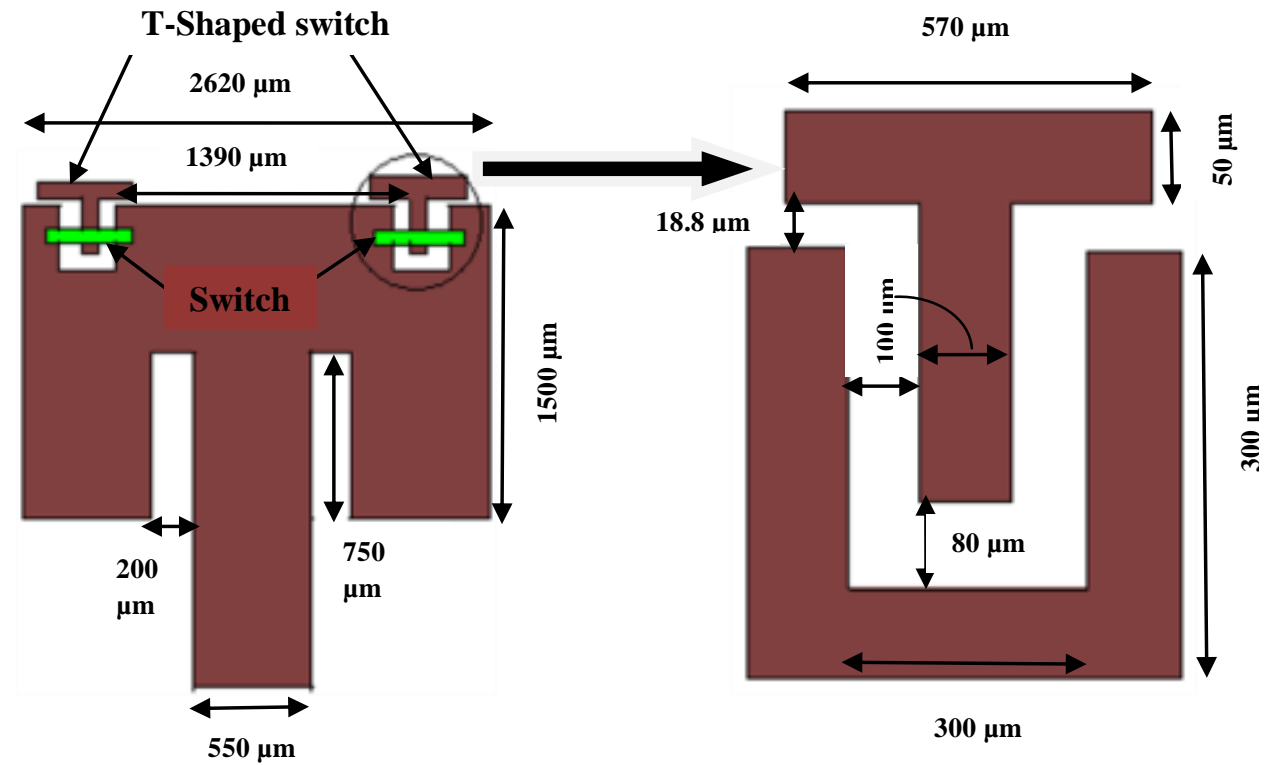

Fig. 9 Layout structure of Frequency Reconfigurable Patch antenna element with two independent Switches

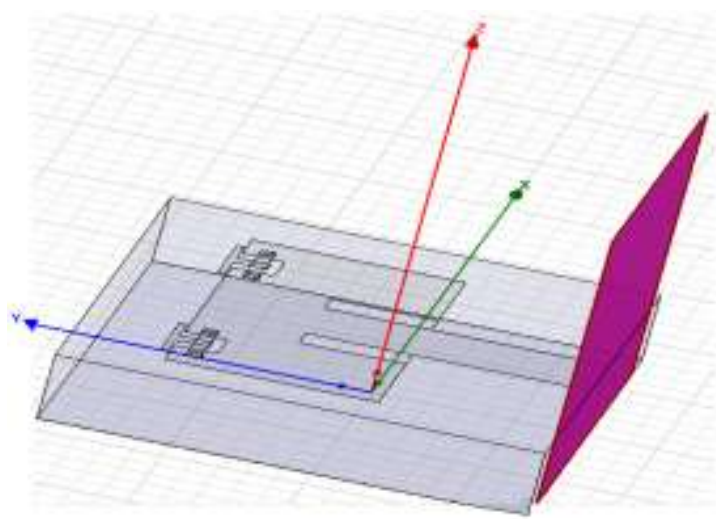

Fig. 10 A Ka-Band Reconfigurable Patch antenna structure in HFSS simulator

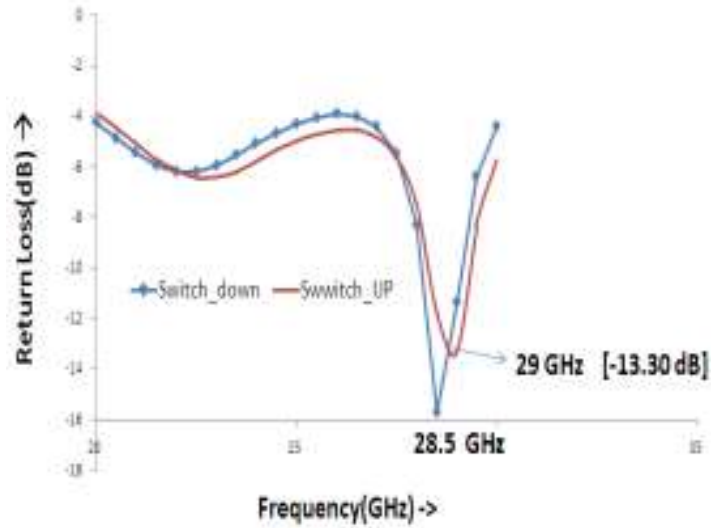

Fig. 11 Measured return loss demonstrating frequency reconfigurability with MEMS switches

\section{CONCLUSION}

This article presents the design and simulation of RF MEMS capacitive type shunt switch and K- Band SPDT switch and Ka-Band Reconfigurable patch antenna as major applications to validate our design concepts. The electromagnetic simulation results indicated that return loss is better than $10 \mathrm{~dB}$ at lower frequency and Insertion loss is less than $0.3 \mathrm{~dB}$ and Isolation is better than $20 \mathrm{~dB}$ which is good enough for the reconfigurable devices. These results indicate that the proposed SPDT switch is of small size and offers low loss by using the capacitive-contact RF MEMS switch. A novel frequency reconfigurable patch antenna with integrated MEMS switches was also simulated. This patch has a reconfigurability bandwidth of $500 \mathrm{MHz}$ ( $28.5 \mathrm{GHz}$ to $29 \mathrm{GHz}$ ). 


\section{REFERENCES}

[1] P.D. Grant, M.W. Denhoff, and R.R. Mansour, "A Comparison between RF MEMS Switches and Semiconductor Switches," ICMEMS 2004: MEMS, NANO and Smart Systems, 2004 Proceedings, Aug. 2004, pp. 515- 521.

[2] G. M. Rebeiz, and J. B. Muldavin, "RF MEMS Switches and Switch Circuits", IEEE Microwave Magazine, Dec. 2001.

[3] J. J. Yao, "Micro Electromecahnical RF Switch", United States Patent, Patent Assignee: Rockwell International Corporation, PatentNo.5578976, Nov.1996.

[4] D. Peroulis, S. Pacheco, K. Sarabandi, and L .P. B, Katehi, "MEMS Devices for High Isolation Switching and Tunable Filtering", IEEE MTT-S Digest, p.1217-1220, 2000

[5] J.B. Muldavin and G. M. Rebeiz, "Inline Capacitive and DC Contact MEMS Shunt Switches", IEEE and Wireless Components Letters, Vol.11, No.8, August 2001.

[6] J. B. Muldavin, and G. M. Rebeiz, "High Isolation Inductively-Tuned X Band MEMS Shunt switches", IEEE MTT-S Digest, p.169$172,2000$.

[7] J. Rizk, G. L. Tan, J. B. Muldavin, and G. M. Rebeiz, "High-Isolation W-Band MEMS Switches", IEEE Microwave and Wireless Components Letters, Vol.11, N.1, January 2001.

[8] P. Sharma, S.K. Koul, and S. Chandra, “ Studies on RF MEMS Shunt switch,” Indian Journal of Pune \& Applied Physics ,Vol. 45,April 2007 , pp. $387-394$.

[9] Mafinejad, A.Z. Kouzani, K. Mafinezhad, and D. Izadi, "Design and Simulation of a RF MEMS Shunt Switch for Ka and V Bands and the Impact of Varying Its Geometrical Parameters,” IEEE International Midwest Symposium, pp. 623 - 626, 2009.

[10] J. B. Muldavin and G. M. Rebeiz, "High isolation MEMS shunt switches-Part 2: Design," IEEE Trans. Microwave Theory Tech., vol. 48, pp. 1053-1056, June 2000.

[11] J. B. Muldavin and G. M. Rebeiz, "High isolation MEMS shunt switches-Part 1: Modeling," IEEE Trans. Microwave Theory Tech., vol. 48, pp. 1045-1052, Jun 1999.

[12] E. R. Brown, "RF-MEMS switches for reconfigurable integrated circuits," IEEE Trans. Microwave Theory Tech., vol. 46, no. 11, pp. 1868- 1880, Nov. 1998

[13] I.J. Cho, T. Song, S.H. Baek, and E. Yoon, "A low voltage and low-power RF MEMS series and shunt switches actuated by combination of electromagnetic and electrostatic forces," IEEE Tranactions on Microwave Theory and Techniques, vol. 53, no. 7, 2005 .

[14] M.A. Llamas, D. Girbau, E.Pausas, L. Pradell, S. Aouba, C. Villeneuve, V. Puyal, P. Pons, R.Plana, S. Colpo, and F. Giacomozzi “ Capacitive and Resistive RF-MEMS switches 2.5-D \& 3-D Electromagnetic and circuit modelling," Proceedings of 2009 IEEE Int. Conf. on Electron devices February 11-13, 2009, Spain.

[15] M. Tang, W. Palei, W. L. Goh, A. Agarwal, L. C. Law, and A. Q. Liu, "A Single-Pole Double-Throw (SPDT) Circuit Using Deep Etching Lateral Metal-Contact Switches," IEEE MTT-S International Microwave Symposium digest IEEE MTT-S International Microwave Symposium, July 2004, pp.581-584.

[16] R. N. Simons, D. Chun, and L.P.B. Katehi, "Polarization Reconfigurable Patch Antenna Using Microelectromechanical Systems (MEMS) Actuators," Proc. IEEE. 2002. 